\title{
Energy recovery from unused and expired medicines
}

\author{
P. De Filippis, B. de Caprariis, M. Scarsella \& N. Verdone \\ Chemical Engineering Department, Sapienza University of Rome, Italy
}

\begin{abstract}
Production and consumption of pharmaceuticals in the world are continuously growing. An analogous trend can be observed for unused and expired medicines, actually estimated in high-income countries to be greater than $40 \%$ of the overall production of medicines. Thus, a correct disposal of this class of waste is assuming increasing importance. Medicine wastage has, in fact, a huge impact worldwide, more than in monetary terms especially for its potential environmental impact such as contamination of groundwater and development of antimicrobial resistance.

The two main options for disposing pharmaceuticals are: landfill and thermal destruction, the latter being the best disposal method currently available. High burn temperature and long combustion retention times assure that all organic waste components are effectively destroyed, while effective pollution control systems deal with exhaust gases and residues from the incinerated pharmaceuticals. An alternative to incinerators is the use of existing industrial furnaces, such as cement kilns or foundries that provide a viable and cheap alternative to building economically expensive specific hazardous waste combustors.

Considering that in unused and expired medicines the packaging materials constitute the major amount of the waste, the alternatives are the disposal of whole packaged pharmaceutics or the safe disposal of the pharmaceutics only, after removal of the packaging. But this last option implies a high additional cost.

The object of this paper is to investigate, on a stock of unused and expired medicines representative of the Italian market, the potentiality of a pyrolysis process as a safe disposal method while providing for energy recovery. Keywords: pharmaceuticals, disposal, pyrolysis, energy recovery.
\end{abstract}




\section{Introduction}

The use of pharmaceuticals is continuously growing: the global prescription and non-prescription consumption has exceeded US\$ 316 billion in 2000, with a worldwide increase in the 1990-2000 decade over 180\% [1]. In the US alone was estimated an increase from 2 billion to 3.9 billion prescription numbers yearly between 1999 and 2009 [2].

This trend results in an analogous growth of the unused and expired medicines, actually estimated in high-income countries greater than $40 \%$ of the overall medicines production [3]. In the US a yearly quantity of such special waste of about 100 Ktons was estimated [4].

As a consequence the medicines wastage has a huge impact worldwide, over than in monetary terms especially for its potential environmental impact.

Improperly disposed medicines can in fact enter water system. In the past years several reports and articles were published about detection of pharmaceutical compounds and their metabolites in the environment and in surface and drinking water [5].

Although most of the medications and their by-products are found in water at very low concentrations (of the order of nanograms to micrograms per liter) [5], even low-level exposure to some of these chemicals may cause serious chronic effects [6]. Potential problems include abnormal physiological processes, reproductive impairment, increased incidences of cancer, and development of antimicrobial-resistant organisms. However the effects of many chemicals on humans and the environment are not yet completely understood. Furthermore, little is known about possible synergistic or antagonistic interactions between chemicals. Evidence indicates that some medications may degrade into more persistent and/or toxic compounds over time.

Other than human excretion of pharmaceuticals and their metabolites into sewage [5], the major factor responsible for their occurrence in the environment is the improper disposal of unused and expired medicines.

It is necessary to distinguish the disposal of this special waste by consumers and the disposal after the collecting, managed by private or public companies. For the consumers the three usual disposal methods for unused and expired medicines are flushing them down the toilet and the sink, throwing them in the garbage, or, more correctly, returning them to the pharmacy. Even if wastewater treatment plants can reduce the concentration of some pharmaceuticals introduced through the sewer system, they are often ineffective to totally remove them and their by-products. Analogously, when unused and expired medicines are thrown in the garbage, they end up in landfills with the potential to reach groundwater and waterways as leachate [7], because of poorly engineered or unlined landfill sites. The limits of the treatment plants of leachates, anyway, are analogous to those reported for the wastewater treatment plants.

Several are the options for disposing collected pharmaceuticals: landfill (with or without previous encapsulation or inertization or chemical inactivation), dilution with water and disposal in sewage treatment plants and, analogously, 
mixing with large volumes of generic wastes and disposal in landfill (only for specific classes of medicines in limited quantities), incineration.

Thermal destruction in an incinerator is the best disposal method currently available: high burn temperatures and long combustion retention times assure that all organic waste components are effectively destroyed, while effective pollution control systems deal with exhaust gases and residues from the incinerated pharmaceuticals. The use, to this aim, of existing industrial plants (such as cement kilns, foundries or thermal power stations) provides a viable and cheap alternative to build economically expensive high temperature incinerators or specific hazardous waste combustors.

Another fundamental aspect to consider is the packaging. World demand for pharmaceutical packaging products is forecast to expand 5.5 percent annually to US\$ 62 billion in 2015 [8]. Considering that packaging materials (paper, cardboard, plastic, aluminium and glass) constitute the major component of the unused and expired medicines and that the removal of such materials can be an high additional cost, energy recovery from this special waste could represent an interesting alternative to the existing disposal methods. At present in our knowledge there is only one available technology for this aim, based on a recent patent [9] that is claimed to have found application in Canada.

The object of this paper is to evaluate, on a stock of unused and expired medicines representative of the Italian market, the potentiality of a pyrolysis process as a safe disposal method while providing for energy recovery.

\subsection{The European and Italian situation}

In the last five years within the European Union, Italy stood at the fifth position on the yearly total expenditure on pharmaceuticals/capita at purchasing power parity [10]. In the 2010 the total expenditure on pharmaceuticals was more than 26 billion Euros, corresponding to about 1.8 billion packages, i.e. 30 packages/capita [11].

Such enormous quantity of pharmaceuticals generates a consequently large volume of unused and expired products to dispose safely. Moreover in Italy, as well as in the rest of Europe, being effectively prohibited the use of tablet counters for counting and dispensing bulk packaged tablets, all the prescriptions and non prescriptions medicines are packaged by manufacturers in number of doses often greater to what necessary. In the US, while the non prescription medicines (the so-called "over-the-counter medicines") are packaged for retail by the manufacturers, most prescriptions in tablets or capsules are bulk packaged by the producers and dispensed in the exact prescribed number of doses by the pharmacy in a simple package (generally a plastic bottle). Over than the volume of packaging, this reduces the medicines that remain unused in the households. Notwithstanding it, US remain the largest consumer of pharmaceutical packaging, with a demand of about US\$ 316 billion in 2010 [8].

Following the European Waste Catalogue (EWC) and hazardous waste list [12], to medicines that are not cytotoxic or cytostatic (for which the incineration is mandatory) are assigned the codes 180109,180208 and 2001 32. Most European countries have take-back programs for unused or expired medications. 
In Italy collection of unused and expired medicines is organized on a municipal basis: collection points for private citizens are located generally near (or into) the pharmacies and at the Local Health Units. In Rome, for example, are present 650 collection points managed by the local municipal company (AMA). For the disposal of unsold medicines from pharmacies and wholesalers, a number of authorized companies provide the pharmaceutical industry with an integral management (tracking, collection and environmentally safe destruction) of these products.

\section{Experimental}

Medicines are very inhomogeneous, being produced in various pharmaceutical forms like tablets, capsules, syrups, etc. and also variously packaged. The typical composition of these products is reported in Table 1.

Table 1: $\quad$ Typical composition of medicines.

\begin{tabular}{lc}
\hline \multicolumn{1}{c}{ Category } & Weight $\%$ \\
\hline Paper and cardboard & $20 \div 25$ \\
Blister (plastic and aluminium) & $7 \div 10$ \\
Glass & $15 \div 20$ \\
Pharmaceutical speciality & $35 \div 50$ \\
Pharmaceutical principle & $2 \div 4$ \\
\hline
\end{tabular}

\subsection{Materials}

The experimental work was performed on a stock sample representative of the Italian situation. In Table 2 the distribution of the different pharmaceutical forms in the stock sample is reported.

Table 2: Distribution of the pharmaceutical forms in the stock sample.

\begin{tabular}{lc}
\hline \multicolumn{1}{c}{ Pharmaceutical form } & Pieces \% \\
\hline Gaseous (sprays + aerosols) & 2 \\
Liquids (injections + syrups + eyedrops, etc.) & 36 \\
Semi-liquids (emulsions, gels, etc.) & 6 \\
Solids (tablets, capsules, powders, granules, etc.) & 56 \\
\hline
\end{tabular}

Because medicines are a very heterogeneous material, the whole sample was ground and mixed before its characterisation and use; the obtained powder was then collected in sealed polyethylene bins. Glass bottles of syrup were taken out before grounding and to take them into account their content was mixed to the ground medicines while the glass bottles were considered in the ashes.

The main physical and chemical characteristics of the powder obtained from the collected sample of expired and unused medicines are reported in Table 3. 
Table 3: $\quad$ Physical and chemical characteristics of the ground sample.

\begin{tabular}{cc}
\hline Parameter & 27 \\
\hline Moisture (\%) & 58 \\
Volatile substance (\% dry basis) & 24 \\
Fixed carbon (\% dry basis) & 18 \\
Ash (\% dry basis) & $<1.0$ \\
Size (mm) & 19.6 \\
High heating value as received $(\mathrm{MJ} / \mathrm{kg})$ & \\
\hline Elemental analysis (mass \% dry basis) & 47.12 \\
Carbon & 5.59 \\
Hydrogen & 0.51 \\
Nitrogen & 28.48 \\
Oxygen & 0.2 \\
Sulphur & $<0.1$ \\
Chlorine &
\end{tabular}

\subsection{Experimental equipment and procedure}

The experimental apparatus used in this work is a small-scale continuous pyrolysis unit consisting in a hopper and feed screw, an electrically heated pyrolysis reactor, two condensers and an after burner chamber where incondensable gas and vapors are sent.

A scheme of the experimental apparatus is reported in Figure 1.

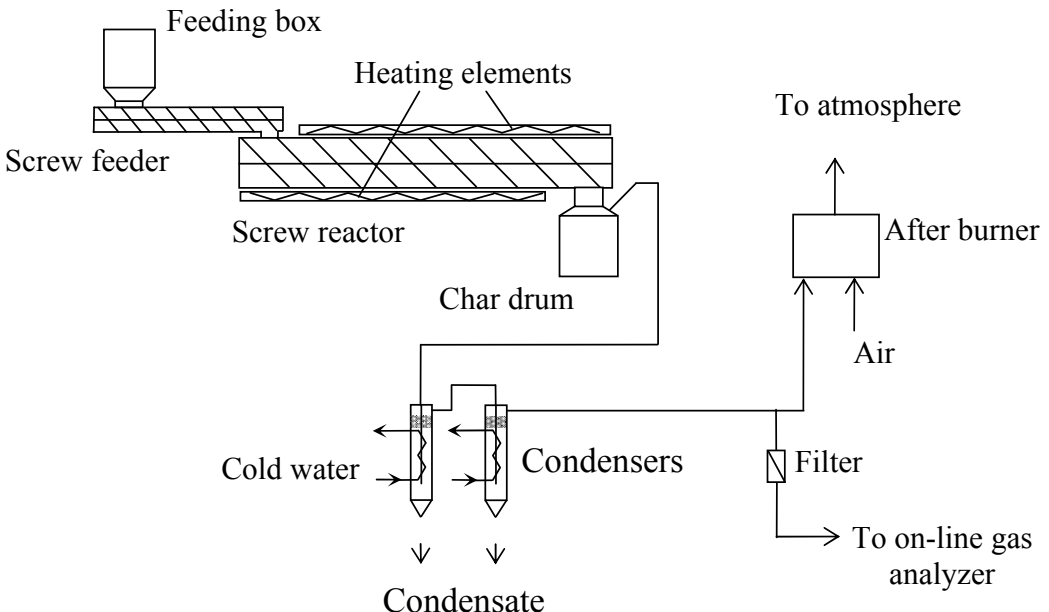

Figure 1: Scheme of the experimental pyrolysis apparatus. 
Two condensers disposed in series were used to ensure the complete condensation of all the vapours. In the first one, the water vapour condensation mainly occurs, while in the second condenser the oil and the residue water are collected.

The pyrolysis tests were conducted in a slow pyrolysis regimen at a temperature of $650{ }^{\circ} \mathrm{C}$ with a heating rate of about $90^{\circ} \mathrm{C} / \mathrm{min}$ and with a high temperature residence time of $17 \mathrm{~min}$. Before use the feed was partially dried to a water content of $5 \%$.

The gas from the condensers was analyzed on-line using a Siemens Ultramat 23 Analyzer for $\mathrm{CO}, \mathrm{CO}_{2}$ and $\mathrm{CH}_{4}$ and off-line by gas chromatography (HP 5890 series II) for hydrogen determination. Elemental analyses of condensed oil and char were performed using an Eurovector EA3000.

\section{Results and discussions}

From Table 1 it is interesting to note that the pharmaceutical principles, that should represent the dangerous molecules in this kind of waste, are only a very small amount of the whole collected mass of medicines and in the considered sample it was no more than $2.5 \%$ by weight, being about $60 \%$ the weight of packaging and $40 \%$ the amount of total pharmaceutical specialities (liquid or solid formulation). Also the very low amount of chlorine, well below the limit foreseen for mandatory incineration, deserves to be emphasized.

On these bases it could be interesting to explore the potentiality of a different thermal destruction technology, in order to obtain an energy recovery in a more versatile form than the heat yielded from incineration.

The explored technology was the pyrolysis, due to the capability of this process to produce liquid combustible that has advantages in transport, storage, combustion and flexibility in marketing.

While incineration processes operate in excess of oxidizing agent, pyrolysis processes consist in a thermal degradation either in the complete absence of oxidizing agent, or with such a limited supply that gasification does not occur to an appreciable extent. Relatively low temperatures are employed, between 500 and $800{ }^{\circ} \mathrm{C}$, compared to 800 to $1000{ }^{\circ} \mathrm{C}$ in gasification and 800 to $1200{ }^{\circ} \mathrm{C}$ in incineration. On the contrary of what happens in other thermal technologies, three products are usually produced from pyrolysis: gas, pyrolysis oil and char. Pyrolysis oil constitutes generally the most important fraction, the relative proportions of the three fractions depending on the pyrolysis method, the characteristics of the feed and the reaction parameters.

The results of pyrolysis tests in the chosen operative conditions are summarized in Table 4.

The oil was obtained by condensation of the pyrolysis vapours. The condensed phase contains about $20 \%$ by weight of water, produced from the evaporation of the residual moisture of the initial feed and from the decomposition of the molecule functional groups during the pyrolysis process. Before analysis the oil was dried up and weighed. 
Table 4: Results of the pyrolysis tests.

\begin{tabular}{clll}
\hline Parameter & Char & Oil & Gas \\
\hline Total amount (\% wt.) & 44 & 32 & 25 \\
High heating value (MJ/kg) & 14.1 & 25.5 & 16.5 \\
Elemental analysis (\% wt dry basis.) & & & \\
C & 39.87 & 64 & - \\
H & 1.51 & 9.5 & - \\
N & 0.29 & 0.5 & - \\
O & 16.52 & 25.7 & - \\
S & 0.25 & 0.3 & - \\
Cl & n.d. & n.d. & 0.23 as HCl \\
Ashes & 41.8 & - & - \\
\hline
\end{tabular}

The elemental analysis of the obtained oil was performed and the results are reported in the third column of the Table 4 . The amount of oil is the $57 \%$ by weight of the pyrolysis products and the $32 \%$ of the initial product. Considering that slow pyrolysis favours gas production, the percentage of liquid obtained is relatively high, and represents an encouraging result. The slow pyrolysis is also the less energy consuming process and so it is recommended to handle with a low quality fuel.

The oil heating value (HHV), that is $25.5 \mathrm{MJ} / \mathrm{kg}$, was calculated using the Dulong equation:

$H H V(M J / k g)=32,79 w_{C}+150,4\left(w_{H}-1 / 8 w_{O}\right)+9,26 w_{S}+4,97 w_{O}+2,42 w_{N}$

where $w_{i}$ are the weight elemental fraction calculated from the elemental analysis.

Due to its composition and heating value pretty good, the oil can be a competitive product in the market to produce an upgraded combustible oil to be used as fuel for energy production and for transportation.

From Table 4 it can be noticed that the results are overall very similar to that generally obtained from cellulosic biomasses [13], the only difference being in the content of ashes, that reflects the relevant quantity of inorganic materials (glass and in less amount aluminium) present in the medicines packaging.

The gas produced during the process, mainly constituted by $\mathrm{CO}_{2}$ and $\mathrm{CO}$ with minor amount of $\mathrm{CH}_{4}$ and $\mathrm{H}_{2}$, shows a calculated heating value of about 13 $\mathrm{MJ} / \mathrm{Nm}^{3}$. It can be used to supply part of the energy requested for the feed drying and the pyrolysis process.

From these results, it is evident that pyrolysis allows to obtain from medicine waste a commercial combustible oil and to reduce at least by the $60 \%$ by weight the material to be sent into hazardous waste landfill. Furthermore it is possible to recover energy also from both the produced gas and the char, decreasing even more the amount of waste. 


\section{Conclusions}

Expired and unused medicines are generally classified, if otherwise not proved, as hazardous wastes. As a consequence the final destination of this special waste is the disposal in hazardous waste landfill or incineration. However, when considering their composition it is evident that the packaging material represents more than $50 \%$ of the whole product, while water and excipients constitute over than $45 \%$. Notwithstanding this evidence the safe disposal of the pharmaceutics only, after removal of the packaging, implies a high additional cost and is not economically viable. Furthermore, potentially dangerous elements such as chlorine are in such a limited amount that they do not constitute a problem for the choice of the thermal treatment process.

In the paper a preliminary study on the application of pyrolysis for the thermal destruction of this waste with a contemporary recovery of energy in a valuable form was presented. The data reported show that the pyrolysis process can represent a viable alternative to the standard applied thermal technologies.

\section{References}

[1] The World Medicines Situation, World Health Organization. Geneva, Switzerland. 2004. Available at http://apps.who.int/medicinedocs/en/ d/Js6160e/2.html. [Accessed February, 20, 2012].

[2] Prescription Drug Trends. Kaiser Family Foundation. 2010. Available at http://www.kff.org/rxdrugs/upload/3057-08.pdf. [Accessed February, 20, 2012].

[3] Green Pharmacy Program - Preliminary Data Report. Teleosis Institute. 2008. Available at www.teleosis.org/pdf/GreenPharmacy Full PreliminaryReport.pdf. [Accessed February, 20, 2012].

[4] Donn J, et al., AP Impact: Health care industry sends tons of drugs into nation's wastewater system. April 2010. Available at http://hosted.ap.org/specials/interactives/pharmawater_site/sept14a.html. [Accessed February, 20, 2012].

[5] Pharmaceuticals in Drinking-water. World Health Organization. Geneva, Switzerland. 2011. And references reported therein. Available at http://www.who.int/water_sanitation_health/publications/2011/pharmaceuti cals_20110601.pdf. [Accessed February, 20, 2012].

[6] Zuccato E., Castiglioni S., Fanelli R., Reitano G., Bagnati R., Chiabrando C., et al., Pharmaceuticals in the environment in Italy: causes, occurrence, effects and control. Environ Sci Pollut Res, 13, pp 15-21, 2006.

[7] Barnes K.K., Christensen S.C., Kolpin D.W., Focazio M.J., Furlong E.T., Zaugg S.D., et al., Pharmaceuticals and other organic waste water contaminants within a leachate plume downgradient of a municipal landfill. Ground Water Monit Rem 24, pp 119-126, 2004.

[8] World Pharmaceutical Packaging. Industry Study with Forecasts for 2015 and 2020. The Freedonia Group, Study \#2765, June 2011. 
[9] Clarke S., Process for the Thermal Treatment of Pharmaceutical Waste Material. US Patent 2008/0179257 A1.

[10] OECD Health Data 2011, November 2011. Available at http://www.oecd.org/document/16/0,3746,en 2649 $339292085200 \quad 1 \quad 1$ 1 1,00.html. [Accessed February, 20, 2012].

[11] Gruppo di lavoro OsMed. L'uso dei farmaci in Italia. Rapporto nazionale anno 2010. Il Pensiero Scientifico Editore, Roma. 2011. Available at http://www.iss.it/binary/pres/cont/OSMED 2010.pdf. [Accessed February, 20, 2012].

[12] Commission Decision 2000/532/EC of 3 May 2000 replacing Decision 94/3/EC establishing a list of wastes pursuant to Article 1(a) of Council Directive 75/442/EEC on waste and Council Decision 94/904/EC establishing a list of hazardous waste pursuant to Article 1(4) of Council Directive 91/689/EEC on hazardous waste.

[13] Mohan D., Pittman C.U., Steele P.H., Pyrolysis of wood/biomass for biooil: A critical review. Energy Fuels, 20 (3), pp 848-889, 2006. 